\title{
Is There any Association Between the Functional Variants of the NOS3 Gene and Psoriasis?
}

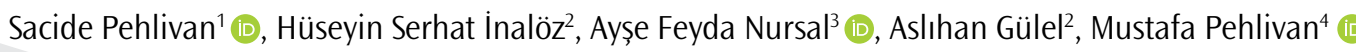

Introduction: Psoriasis (Ps) is a chronic, immune-mediated inflammatory skin disorder with an incompletely understood etiology. The aim of this study was to investigate the relationship between the suspectibility to Ps and G894T (rs1799983) and variable number tandem repeat (VNTR) variants of the endothelial nitric oxide synthase (NOS3) gene.

Methods: This is a case-controlled study that included 74 Ps patients in addition to 74 matched healthy unrelated controls from the same locality. The NOS3 gene variants were analyzed by polymerase chain reaction (PCR) and/or PCR- restriction fragment lenght polymorphism (PCR-RFLP).

Results: The NOS3 G894T TT genotype and T allele were more common in the Ps group compared to the healthy controls $(p=0.000, p=0.001$, respectively). The NOS3 VNTR variant BB genotype and B allele were higher in the patient group than in the control group $(p=0.005, p=0.000$ respectively). The NOS3 VNTR AA genotype was lower in the patient group $(p=0.027)$. However, a stratified analysis including arthritis, the Ps area and severity index (PASI), the age of onset, and family history revealed no significant correlation between the NOS3 G894T and NOS3 VNTR genotypes $(\mathrm{p}>0.05)$.

Conclusion: These results suggest that the NOS3 G894T and VNTR variants are associated with Ps in a Turkish cohort. However, future studies are needed to understand the genetic role of the NOS3 variants in the development of Ps.

Keywords: Psoriasis, endothelial nitric oxide synthase gene, G894T, variable number tandem repeat

ORCID IDs of the authors: A.F.N. 0000-0001-76391122; M.P. 0000-0002-6692-085X; S.P. 0000-0003$1272-5845$.

${ }^{1}$ Department of Medical Biology, İstanbul University İstanbul School of Medicine, İstanbul, Turkey

${ }^{2}$ Department of Dermatology, Gaziantep University School of Medicine, Gaziantep, Turkey ${ }^{3}$ Department of Medical Genetics, Hitit University School of Medicine, Çorum, Turkey

${ }^{4}$ Department of Hematology, Gaziantep University School of Medicine, Gaziantep, Turkey

Address for Correspondence:

Ayșe Feyda Nursal

E-mail: feydanursal@hotmail.com

Received: 06.09.2017

Accepted: 08.12.2017

C Copyright 2018 by Available online at istanbulmedicaljournal.org

\section{Introduction}

Psoriasis (PS) (MIM 177900) is a chronic inflammatory skin disease that manifests as red, scaly skin plaques with various degrees of severity and affects almost $2 \%$ of the population (1). Psoriasis vulgaris is the most common type of the disease. Several factors associated with the skin, immune system, and human genome have been implicated in the pathogenesis of Ps. Histologically, Ps is characterized by the hyperproliferation and impaired differentiation of keratinocytes, dilated hyperplastic blood vessels, and inflammatory infiltration of leucocytes mainly into the dermis (2). It is suggested that the infiltration of activated T-cells induces keratinocyte proliferation in Ps (3).

Nitric oxide (NO), a multifunctional secondary messenger,which acts as a vasodilator, immunomodulator, antioxidant, and bactericide, contributes to the modulation of gene expression, and alters their functions thorough the nitrosylation of involved proteins. NO plays a role in the maintenance of skin homeostasis,and it is a strong regulator of keratinocyte growth and differentiation (4). NO is produced in and released from keratinocytes in high amounts and is the key inhibitor of cellular proliferation and inducer of differentiation in vitro. NO is synthesized from L-arginine by three NO synthases (NOS), namely NOS1 or neuronal, NOS2 or inducible, and NOS3 or endothelial NO synthase (5). These NOS are expressed by skin cell types, and NOS2 is expressed by keratinocytes in Ps and other inflammatory skin disorders (6). The NOS3 gene is found on chromosome 7q35-36, within a length of $4.4 \mathrm{~kb}$ (7). The NOS3 gene has several allelic variants, and some of them are functional. The exon 7 Glu298Asp missense variant (rs1799983) and the intron-4 27-bp variable number tandem repeat (VNTR) variant of NOS3 are proposed to be related with NOS3 dysfunction, resulting in impairment of NO production (8).

Therefore, in present study, we aimed to investigate the relationship of Ps with the NOS3 gene functional variants in a Turkish cohort. The results obtained from the study were compared both between each other and with the clinical parameters. 


\section{Methods}

\section{Study Population}

In total, 74 Ps patients (mean age: 42 years; male-to-female ratio 1.1:1) and 74 healthy controls participated in the study. Both the study group and control group were of Turkish origin, from the south of Turkey. Clinical diagnosis was performed by dermatologists, and all the patients had at least two skin lesions. The participants were well informed about the nature of this study and they participated voluntarily. Clinical data were collected from all the patients. Disease severity was quantified by the psoriasis area and severity index (PASI) (9). For all the patients, the PASI score was recorded. In our study, patients with Ps were sorted into two groups according to their PASI score. Based on the median distribution, PASI $\leq 10$ was defined as mild Ps (Type I) and PASI>10 (Type II) as severe Ps. High PASI score represents a high degree of psoriatic severity. Seventy-four healthy subjects, individually matched to patients by both gender and age, were recruited as controls. Informed written consent was obtained from all individuals before enrollment in the study, according to the ethical guidelines of the Declaration of Helsinki, and the investigation was approved by the Gaziantep University Instutional Ethical Committee.

\section{Genotyping Analysis}

DNA was extracted from whole blood samples using a salting out method (10). The NOS3 gene variant G894T was analyzed by polymerase chain reaction-restriction fragment lenght polymorphism (PCR-RFLP) method as described previously (11). The G894T variant was genotyped by PCR amplification using the following primers 5'-CATGAGGCTCAGCCCCAGAAC-3' (forward) and 5'-AGTCAATCCCTTTGGTGCTCAC-3' (reverse). The PCR products were digested using Mbol enzyme (Invitrogen, Carlsbad, CA, USA) at $37^{\circ} \mathrm{C}$ overnight. PCR products were loaded onto $3 \%$ agarose gels previously stained with ethidium bromide and were visualized by using an ultraviolet transilluminator.The $206 \mathrm{bp}$ products had a consistent restriction site resulting in a $119 \mathrm{bp}$ and an $87 \mathrm{bp}$ fragment.

The 27 bp-VNTR AB genotype in intron 4 of NOS3 were evaluated by PCR amplification using primers 5'-AGGCCCTATGGTAGTGCCTTT-3' (forward) and 5'-TCTCTTAGTGCTGTGGTCAC-3' (reverse) (12). The amplified products were separated by electrophoresis on a $3 \%$ agarose gel and visualized by ethidium bromide staining. The wild type allele contained five tandem repeats of $27 \mathrm{bp}$ and $420 \mathrm{bp}$, and the mutant allele four tandem repeats of $27 \mathrm{bp}$ and $393 \mathrm{bp}$.

\section{Statistical Analysis}

Statistical analysis was performed using the SPSS (Statistical Package for Social Sciences) version 14.0 for Windows (SPSS Inc., Chicago, IL, USA). Statistical significance of differences between groups was estimated by logistic regression analysis. Odds ratio (OR) and 95\% confidence interval (Cl) were also calculated. Distribution of the NOS3 G894T and VNTR variants and deviation from the HardyWeinberg equilibrium (HWE) for each control group were examined using the chi-square test. All the analyses were two-tailed, and a $p<0.05$ was considered to be significant.

\section{Results}

This analysis included 74 Turkish patients with Ps and 74 age- and sex-matched controls. The mean age of the patients was 42 years. Tables 1 and 2 demonstrate the genotype distribution and allele frequency of the G894T and VNTR variants of the NOS3 gene in the patients and the controls.

\section{NOS3 G894T}

Frequencies of the GG, GT, and TT genotypes for the NOS3 G894T variant were $50 \%, 32.4 \%$, and $17.6 \%$, respectively, among the patients, and $64.9 \%, 35.1 \%$, and $0 \%$, respectively, among the controls. The alleles and genotypes of the NOS3 G894T variant were found to be significantly associated between the patients and controls. Patients with the NOS3 TT genotype had a 0.542-fold increased risk for Ps (OR=0.542, 95\% Cl: 0.280-1.048; $p=0.000$ ) (Table 1). Allelic frequencies of the NOS3 G894T variant among the patients and controls were $66.2 \%$ and $82.4 \%$, respectively, for allele $\mathrm{G}$ (wild type) and $33.8 \%$ and $17.6 \%$, respectively, for allele $\mathrm{T}$ (mutant). There was a significant association between the allele frequencies of the NOS3 G894T variant between patients and controls. The NOS3 G894T T allele was higher in patients with Ps (OR=0.418, 95\% Cl: 0.191-0.837; $p=0.001$ ) (Table 1).

\section{NOS3 VNTR}

For the NOS3 VNTR variant, a significant difference in both the genotype distribution and allele frequency between the Ps patients and control subjects was observed (Table 2). The NOS3 VNTR AA genotype was lower in the patient group $(O R=0.442,95 \% \mathrm{Cl}$ : $0.223-0.872 ; p=0.005)$, while the NOS3 VNTR variant BB genotype was higher $(\mathrm{OR}=0.130,95 \% \mathrm{Cl}: 0.028-0.600 ; \mathrm{p}=0.005)$.

Allelic frequencies of the NOS3 VNTR variant among the patients and controls were $67.6 \%$ and $84.5 \%$, respectively, for allele A (wild type), and $32.4 \%$ and $15.5 \%$, respectively, for allele B (mutant). There was a significant association between allele frequencies of NOS3 VNTR between patients and controls $(\mathrm{OR}=2.609,95 \% \mathrm{Cl}$ : 1.487-4.578; $\mathrm{P}=0.000$ ). Allele $\mathrm{B}$ was higher in the patient group than in the control group.

When the patients and controls were compared in terms of HWE, deviations were observed in both NOS3 variants ( $p=0.017$ and $\mathrm{p}=0.005$, respectively) (Table 1 and 2 ).

\section{Clinical Features According to the NOS3 G894T and VNTR Geno- types}

We compared the genotype distribution of the groups with a positive and negative family history in order to establish any possible influence of family history on the relation between the NOS3 genotypes and Ps. The distributions of the NOS3 gene variants according to family history are given Table 3 . We found no significant difference between the groups.

We evaluated the NOS3 G894T and VNTR variants genotype distribution according to arthritis status in patients with Ps. The results are presented in Table 4 . We found no significant difference between the patients and controls. When the patient groups were compared with regard to the presence of arthritis, there was no statistically significant difference between the arthritic (psoriatic arthritis) and non-arthritic (psoriasis vulgaris) groups.

To explore a possible relationship between the NOS3 G894T and VNTR genotypes and PASI scores, we performed stratified analysis (Table 5). There was no statistical difference between the two levels of Ps and the controls.

Ps is clinically divided into Type I (onset before 40 years of age) and Type II (onset after 40 years of age). Type I shows a high degree of 
Table 1. Genotype and allele frequencies of NOS3 gene G894T variant in the patients and the controls

\begin{tabular}{|c|c|c|c|c|c|c|}
\hline \multirow{2}{*}{$\begin{array}{l}\text { NOS3 } \\
\text { G894T }\end{array}$} & \multicolumn{2}{|c|}{ Controls } & \multicolumn{2}{|c|}{ Patients } & \multirow[b]{2}{*}{$\mathrm{OR}(95 \% \mathrm{Cl})$} & \multirow[b]{2}{*}{ p } \\
\hline & $\mathrm{n}^{\mathrm{a}}$ & $\%$ & $\mathrm{n}^{\mathrm{b}}$ & $\%$ & & \\
\hline \multicolumn{7}{|c|}{ Genotypes } \\
\hline GG & 48 & $(64.9)$ & 37 & (50) & $0.824(0.742-0.916)$ & 0.096 \\
\hline GT & 26 & $(35.1)$ & 24 & $(32.4)$ & $1.128(0.571-2.231)$ & 0.862 \\
\hline TT & 0 & (0) & 13 & $(17.6)$ & $0.542(0.280-1.048)$ & 0.000 \\
\hline Total & 74 & (100) & 74 & (100) & & \\
\hline \multicolumn{7}{|l|}{ Alleles } \\
\hline G & 122 & $(82.4)$ & 98 & $(66.2)$ & $0.418(0.191-0.837)$ & 0.001 \\
\hline $\mathrm{T}$ & 26 & $(17.6)$ & 50 & (33.8) & & \\
\hline Total & 148 & (100) & 148 & (100) & & \\
\hline *HWE $p$ & \multicolumn{2}{|c|}{0.066} & \multicolumn{2}{|c|}{0.017} & & \\
\hline
\end{tabular}

Table 2. Genotype and allele frequencies of NOS3 VNTR variant in the patients and the controls

\begin{tabular}{|c|c|c|c|c|c|c|}
\hline \multirow{2}{*}{$\begin{array}{l}\text { NOS3 } \\
\text { VNTR }\end{array}$} & \multicolumn{2}{|c|}{ Controls } & \multicolumn{2}{|c|}{ Patients } & \multirow[b]{2}{*}{ OR ( $95 \% \mathrm{Cl})$} & \multirow[b]{2}{*}{$\mathbf{p}$} \\
\hline & $\mathrm{n}^{\mathrm{a}}$ & $\%$ & $n^{b}$ & $\%$ & & \\
\hline \multicolumn{7}{|c|}{ Genotypes } \\
\hline AA & 53 & (71.6) & 39 & $(52.7)$ & $0.442(0.223-0.872)$ & 0.027 \\
\hline$A B$ & 19 & $(25.7)$ & 22 & (29.7) & $0.817(0.395-1.680)$ & 0.714 \\
\hline BB & 2 & (2.7) & 13 & (17.6) & $0.130(0.028-0.600)$ & 0.005 \\
\hline Total & 74 & $(100)$ & 74 & $(100)$ & & \\
\hline \multicolumn{7}{|l|}{ Alleles } \\
\hline A & 125 & $(84.5)$ & 100 & (67.6) & $2.609(1.487-4.578)$ & 0.000 \\
\hline B & 23 & $(15.5)$ & 48 & (32.4) & & \\
\hline Total & 148 & $(100)$ & 148 & $(100)$ & & \\
\hline *HWE $p$ & 0.850 & 0.005 & & & & \\
\hline
\end{tabular}

Table 3. The relationship between NOS3 gene variants and family history in the patients with Ps

\begin{tabular}{|c|c|c|c|c|c|c|}
\hline & & Family history (+) & Family history (-) & & & \\
\hline & Genotype & $\mathrm{n}^{\mathrm{a}}(\%)$ & $n^{b}(\%)$ & OR & $95 \% \mathrm{Cl}$ & p \\
\hline \multirow[t]{3}{*}{ NOS3 G894T } & GG & $16(47.1)$ & $21(52.5)$ & $1.042^{*}$ & $0.264-4.120^{*}$ & $0.953^{*}$ \\
\hline & GT & $13(38.2)$ & $11(27.5)$ & $2.230^{*}$ & $0.525-9.480^{*}$ & $0.277^{*}$ \\
\hline & $\mathrm{TT}$ & $5(14.7)$ & $8(20.0)$ & $1.450^{\&}$ & $0.426-4.937^{\&}$ & $0.760^{\&}$ \\
\hline \multirow[t]{3}{*}{ NOS3 VNTR } & $\mathrm{AA}$ & $15(44.2)$ & $24(60.0)$ & $0.705^{*}$ & $0.189-2.630^{*}$ & $0.603 *$ \\
\hline & $\mathrm{AB}$ & $13(38.2)$ & $9(22.5)$ & $1.694 *$ & $0.406-7.080^{*}$ & $0.470^{*}$ \\
\hline & BB & $6(17.6)$ & $7(17.5)$ & $1.010^{\&}$ & $0.304-3.358^{\star}$ & $1.000^{\star}$ \\
\hline
\end{tabular}

${ }^{a} \mathrm{n}=34 ; \mathrm{bn}=40 ;$ OR (Cl95\%): Odds Ratio with 95\% Confidence Interval; *OR (95\%Cl) corrected by age and sex, ${ }^{\circledR}$ Fisher's Exact Test; NOS3: Endothelial NO synthase; VNTR: Variable number tandem repeat

familial aggregation, while Type II shows a low degree of familial history (13). In present study, we found no statistically significant association between the NOS3 (G894T and VNTR) genotypes and the onset age (Table 6).

\section{Discussion}

Ps is a chronic inflammatory immunologic genodermatosis, manifested by an increased activity of proliferative keratinocytes. While 
Table 4. The relationship between NOS3 gene variants and arthritis in the patients with Ps

\begin{tabular}{|c|c|c|c|c|c|c|}
\hline & & Arthritis (+) & Arthritis (-) & & & \\
\hline & Genotype & $\mathrm{n}^{\mathrm{a}}(\%)$ & $\mathrm{n}^{\mathrm{b}}(\%)$ & OR & $95 \% \mathrm{Cl}$ & p \\
\hline \multirow[t]{3}{*}{ NOS3 G894T } & GG & $12(52.2)$ & $25(49.0)$ & $1.898^{*}$ & $0.460-7.835^{*}$ & $0.376^{*}$ \\
\hline & GT & $6(26.1)$ & 18 (35.3) & $1.904^{*}$ & $0.418-8.660$ * & $0.405^{*}$ \\
\hline & $\mathrm{TT}$ & $5(21.7)$ & $8(15.7)$ & $1.493^{\alpha}$ & $0.430-5.188^{\varangle}$ & $0.526^{8}$ \\
\hline \multirow[t]{3}{*}{ NOS3 VNTR } & AA & $13(56.5)$ & $26(51.0)$ & $1.020^{*}$ & $0.245-4.244^{*}$ & $0.978^{*}$ \\
\hline & $A B$ & $6(26.1)$ & $16(31.4)$ & $1.397^{*}$ & $0.287-6.792 *$ & $0.679 *$ \\
\hline & BB & $4(17.4)$ & $9(17.6)$ & $1.018^{\&}$ & $0.278-3.722^{\S}$ & $1.000^{\delta}$ \\
\hline
\end{tabular}

${ }^{a} \mathrm{n}=23$; $\mathrm{bn}=51$; NOS3: Endothelial NO synthase; OR (C195\%): Odds Ratio with 95\% Confidence Interval; *0R (95\%Cl) corrected with age and sex, ${ }^{\star}$ Fisher's Exact Test; VNTR: Variable number tandem repeat

Table 5. The relationship between NOS3 gene variants and PASI in patients with Ps

\begin{tabular}{|c|c|c|c|c|c|c|}
\hline & & PASI 1 (PASI $\leq 10)$ & PASI 2 (PASI>10) & & & \\
\hline & Genotype & $\mathrm{n}^{\mathrm{a}}(\%)$ & $\mathrm{n}^{\mathrm{b}}(\%)$ & OR & $95 \% \mathrm{Cl}$ & p \\
\hline \multirow[t]{3}{*}{ NOS3 G894T } & GG & $19(51.4)$ & 18 (48.6) & $0.794 *$ & $0.210-3.002^{*}$ & $0.733^{*}$ \\
\hline & GT & $11(29.7)$ & $13(35.2)$ & $0.785^{*}$ & $0.194-3.002 *$ & $0.735^{*}$ \\
\hline & $\mathrm{TT}$ & $7(18.9)$ & $6(16.2)$ & $0.829^{£}$ & $0.250-2.755^{\&}$ & $1.000^{\&}$ \\
\hline \multirow[t]{3}{*}{ NOS3 VNTR } & $\mathrm{AA}$ & $20(54.1)$ & $19(51.4)$ & $0.906^{*}$ & $0.247-3.324^{*}$ & $0.881^{*}$ \\
\hline & $A B$ & $10(27.0)$ & $12(32.4)$ & $0.695^{*}$ & $0.168-2.872^{*}$ & $0.616^{*}$ \\
\hline & BB & $7(18.9)$ & $6(16.2)$ & $1.206^{\varangle}$ & $0.363-4.004^{\S}$ & $1.000^{\&}$ \\
\hline
\end{tabular}

${ }^{a} \mathrm{n}=37$; bn=37; OR (Cl95\%): Odds Ratio with 95\% Confidence Interval; *OR (95\%Cl) corrected by age and sex, ${ }^{\star}$ Fisher's Exact Test; PASI (psoriasis area severity index); NOS3: Endothelial NO synthase; VNTR: Variable number tandem repeat

Table 6. The relationship between NOS3 gene variants and disease onset in the patients with Ps

\begin{tabular}{|c|c|c|c|c|c|c|}
\hline & & $\begin{array}{c}\text { Early onset }(\leq 40 \text { age }) \\
\text { Type I }\end{array}$ & $\begin{array}{c}\text { Late onset (>40 age) } \\
\text { Type II }\end{array}$ & & & \\
\hline & Genotype & $\mathbf{n}^{\mathrm{a}}(\%)$ & $\mathrm{n}^{\mathrm{b}}(\%)$ & OR & $95 \% \mathrm{Cl}$ & p \\
\hline \multirow[t]{3}{*}{ NOS3 G894T } & GG & $26(53.1)$ & $11(44.0)$ & $1.318^{\&}$ & $0.129-13.499^{\star}$ & $0.816^{\&}$ \\
\hline & GT & $15(30.6)$ & $9(36.0)$ & $1.882^{*}$ & $0.163-21.690^{*}$ & $0.612^{*}$ \\
\hline & TT & $8(16.3)$ & $5(20.0)$ & $1.281^{\&}$ & $0.371-4.422^{£}$ & $0.752^{\&}$ \\
\hline \multirow[t]{3}{*}{ NOS3 VNTR } & AA & $25(51.0)$ & $14(56.0)$ & $0.338^{*}$ & $0.039-2.940^{*}$ & $0.326^{*}$ \\
\hline & $A B$ & 14 (28.6) & $8(32.0)$ & $0.195^{*}$ & $0.018-2.161^{*}$ & $0.183^{*}$ \\
\hline & BB & $10(20.4)$ & $3(12.0)$ & $1.880^{\&}$ & $0.467-7.565^{\AA}$ & $0.523^{\&}$ \\
\hline
\end{tabular}

${ }^{a} \mathrm{n}=49 ;{ }^{\mathrm{b}} \mathrm{n}=25 ;$ * OR $(95 \% \mathrm{Cl})$ corrected with age and sex, ${ }^{\star}$ Fisher's Exact Test; NOS3: Endothelial NO synthase; VNTR: Variable number tandem repeat

the exact cause remains unclear, environmental and genetic factors are believed to be involved in the pathogenesis of Ps. Ps has been related to several gene variants that are implicated in many different processes, such as skin barrier functions and the regulation of inflammatory and immune responses.

Reactive species or free radicals include reactive oxygen, and nitrogen species are called reactive oxygen nitrogen species (RONS). Most of the RONS carry unpaired electrons and are called free radicals. In mammalian species, one of the main functions of specialized enzymes is the production of RONS (14). Skin is the main target of oxidative stress as it is repetitively exposed to UV radiation and other environmental stresses. Therefore, it has been proposed that elevated ROS synthesis, impaired function of antioxidant system, and oxidative stress may be responsible in the pathogenesis of Ps. Involvement of ROS in the etiopathogenesis of Ps has been studied by several researchers in recent years $(15,16)$. A recent study (17) reported significantly high levels of oxidative stress markers, such as plasma or serum malondialdehyde (MDA), and NO end products, in patients with Ps. Besides, blood NO levels were significantly elevated in patients with Ps and exhibited a positive correlation with the severity and duration of the lesions (18-20). Some of these studies, further suggested a positive correlation between the oxidative stress markers and PASI levels and a negative correlation between antioxidant markers and PASI levels in patients with Ps $(18,21)$. Although Tekin et al. (22) demonstrated that pre-treatment NO levels were significantly higher in Ps patients than post-treatment levels and controls, they did not find a relationship between PASI scores and serum nitrite or nitrate. Adversely, it was suggested a positive correlation between the PASI 
and NO levels and thus considered NO to be an important factor in the inflammatory mechanism in Ps (16). Also,it was detected that neutrophils, known as the best source of ROS in organism are increased in psoriatic skin (23).

Ormerod et al. (15) have found high levels of the NOS2 and NOS3 expression in psoriatic lesions, suggesting their impact along with NO in the occurrence and further development of Ps. Recent genome-wide association studies described a novel Ps susceptibility locus tagged by two variants rs4795067 and rs8998802, both of which are in the intronic region of the NOS2 gene (24). Since NOS2 and NOS3 play an important role in the production of NO and the pathogenesis of Ps, we hypothesized that the NOS3 G894T and VNTR variants could be associated with the risk of Ps. Hence, we studied the potential association of the NOS3 G894T and VNTR variants with Ps and tried to correlate the results with the clinical characteristics in this study.

The NOS3 G894T variant has been related to lowered basal NO production and is also reported to have an impact on the function of the NOS3 protein (25). In a previous study conducted on Turkish population, Senturk et al. (26) reported that the frequency of T allele of NOS3 G894T was higher in patients with Ps compared to that in control. Also, Ogretmen et al. (27) showed that the T allele frequency in the NOS3 G894T variant was higher in psoriatic patients than in controls. However, Coto-Segura et al. (6). showed that the NOS3 G894T variant had no association with Spanish patients. The results of our investigation showed a significant association of the NOS3 G894T genotypes with the development of Ps in patients with Turkish ethnicity (Table 1).TheTT genotype and T allele of the NOS3 G894T variant were higher in patients with Ps when compared with the healthy volunteers $(P=0.000, P=0.001$, respectively) (Table 1). Our results are consistent with the results reported by Senturk et al. (26) and Ogretmen et al. (27).

The NOS3 VNTR variant, in repeats of a 27-bp consensus sequence, two alleles that consisted of a common larger allele and a smaller allele, was studied. This variant has been related to alterations in the plasma levels of NO and its metabolites. The 27-bp VNTR plays a cis-acting role in the NOS3 promoter activity and interferes with NOS3 expression (28). The larger allele (B allele) designated as "b-insertion" bears five tandem repeats, and the smaller allele (A allele) "a-deletion" has four repeats (29). Coto-segura et al. (6) declared that the four-repeat allele (mutant allele) was more frequent among the patients with Ps. In present study, similarly, the NOS3 VNTR variant BB genotype and B allele were higher in patients with Ps compared to healthy controls ( $p=0.000$ and $p=0.005$, respectively) (Table 2 ).

Furthermore, we evaluated that relationship between the NOS3 variants genotypes and clinical features (joint involvement, the age of onset, PASI, and family history). However, a stratified analysis according to clinical features revealed no significant correlation between the NOS3 G894T and VNTR genotypes and an increased risk of $\mathrm{Ps}(\mathrm{p}>0.05)$.

\section{Conclusion}

Consequently, our study suggested that the NOS3 G894T and VNTR functional variants may render the Turkish population susceptible to Ps. Such studies may be useful for better understanding of the pathogenesis of Ps and development of new therapeutic approaches for the disease. More studies are required to confirm our findings in a different, larger populations of patients with Ps.

Ethics Committee Approval: Ethics committee approval was received for this study from the ethics committee of Gaziantep University (Approval Date: 19.02.2009; Approval No: 02-2009/30).

Informed Consent: Written informed consent was obtained from all the patients who participated in this study.

Peer-review: Externally peer-reviewed.

Author Contributions: Concept - S.P., H.S.I; Design - H.S.I, M.P.; Supervision - A.F.N., A.G.; Resource - S.P., M.P.; Materials - H.S.I., A.G.; Data Collection and/or Processing - A.G., H.S.I.; Analysis and/or Interpretation - S.P., M.P.; Literature Search - A.F.N., M.P.; Writing - A.F.N., M.P.; Critical Reviews - S.P., M.P.

Conflict of Interest: The authors have no conflict of interest to declare.

Financial Disclosure: The authors declared that this study has received no financial support.

\section{References}

1. Christophers E. Psoriasis-epidemiology and clinical spectrum. Clin Exp Dermatol 2001; 26: 314-20. [CrossRef]

2. Matoshvili M, Katsitadze A, Sanikidze T, Tophuria D, Richetta A, D'Epiro S. The role of nitric oxide in the pathogenesis and severity of psoriasis. Georgian Med News 2014; 234:61-4.

3. Boniface K, Guignouard E, Pedretti N, Garcia M, Delwail A, Bernard FX, et al. A role for T cell-derived interleukin 22 in psoriatic skin inflammation. Clin Exp Immunol 2007; 150: 407-15. [CrossRef]

4. Cals-Gierson MM, Ormerod AD. Nitric oxide function in the skin. Nitric Oxide 2004; 10: 179-93. [CrossRef]

5. Moncada S, Higgs A. The L-arginine-nitric oxide pathway. N Engl J Med 1993; 329: 2002-12. [CrossRef]

6. Coto-Segura P, Coto E, Mas-Vidal A, Morales B, Alvarez V, Díaz M, et al. Influence of endothelial nitric oxide synthase polymorphisms in psoriasis risk. Arch Dermatol Res 2011; 303: 445-9. [CrossRef]

7. Marsden PA, Heng HH, Scherer SW, Stewart RJ, Hall AV, Shi XM, et al. Structure and chromosomal localization of the human constitutive endothelial nitric oxide synthase gene. J Biol Chem 1993; 268: 17478-88.

8. Wang XL, Mahaney MC, Sim AS, Wang J, Wang J, Blangero J, et al. Genetic contribution of endothelial constitutive nitric oxide synthase gene to plasma nitric oxide levels. Arterioscler Thromb Vasc Biol 1997; 17: 3147-53. [CrossRef]

9. de Rie MA, Goedkoop AY, Bos JD. Overview of psoriasis. Dermatol Ther 2004;17: 341-9. [CrossRef]

10. Miller SA, Dykes DD, Polesky HF. A simple salting out procedure for extracting DNA from human nucleated cells. Nucleic Acids Res 1988;16: 1215. [CrossRef]

11. Ozturk E, Balat O, Pehlivan S, Ugur MG, Ozcan C, Sever T, et al. Endothelial nitric oxide synthase gene polymorphisms in preeclampsia with or without eclampsia in a Turkish population. J Obstet Gynaecol Res 2011;37: 1778-83. [CrossRef]

12. Safarinejad MR, Safarinejad S, Shafiei N, Safarinejad S. Effects of the T-786C, G894T, and intron 4 VNTR (4a/b)polymorphisms of the endothelial nitric oxide synthase gene on the risk of prostate cancer. Urol Oncol 2013; 31: 1132-40. [CrossRef]

13. Henseler T, Christophers E. Psoriasis of early and late onset: characterization of two types of psoriasis vulgaris. J Am Acad Dermatol 1985; 13: 450-6. [CrossRef]

14. Weidinger A, Kozlov AV. Biological Activities of Reactive Oxygen and Nitrogen Species: Oxidative stress versus Signal Transduction. Biomolecules 2015; 5: 472-84. [CrossRef] 
15. Ormerod AD, Weller R, Copeland P, Benjamin N, Ralston SH, Grabowksi $P$, et al. Detection of nitric oxide and nitric oxide synthases in psoriasis. Arch Dermatol Res 1998; 290: 3-8. [CrossRef]

16. Zalewska A, Wyczołłkowska J, Narbutt J, Sysa-Jedrzejowska A. Nitric oxide levels in plasma and fibroblast cultures of psoriasis vulgaris patients. J Dermatol Sci 2007; 48: 237-40. [CrossRef]

17. Kadam DP, Suryakar AN, Ankush RD, Kadam CY, Deshpande KH. Role of oxidative stress in various stages of psoriasis. Indian J Clin Biochem 2010; 2: 388-92. [CrossRef]

18. Gabr SA, Al-Ghadir AH. Role of cellular oxidative stress and cytochrome $\mathrm{c}$ in the pathogenesis of psoriasis. Arch Dermatol Res 2012; 304: 451-7. [CrossRef]

19. Gokhale NR, Belgaumkar VA, Pandit DP, Deshpande S, Damle DK. A study of serum nitric oxide levels in psoriasis. Indian J Dermatol Venereol Leprol 2005; 71: 175-8. [CrossRef]

20. Orem A, Aliyazicioglu R, Kiran E, Vanizor B, Cimnocodeit G, Deger O. The relationship between nitric oxide production and activity of the disease in patients with psoriasis. Arch Dermatol 1997; 133:1606-7. [CrossRef]

21. Nemati H, Khodarahmi R, Sadeghi M, Ebrahimi A, Rezaei M, VaisiRaygani A. Antioxidant status in patients with psoriasis. Cell Biochem Funct 2014; 32: 268-73. [CrossRef]

22. Tekin NS, Ilter N, Sancak B, Ozden MG, Gurer MA. Nitric oxide levels in patients withpsoriasis treated with methotrexate. Mediators Inflamm 2006; 2006: 16043. [CrossRef]

23. Turner CP, Toye AM, Jones OTG. Keratinocyte superoxide generation. Free Radic Biol Med 1998;24: 401-7. [CrossRef]
24. Stuart PE, Nair RP, Ellinghaus E, Ding J, Tejasvi T, Gudjonsson JE, et al. Genome-wide association analysis identifies three psoriasis susceptibility loci. Nat Genet 2010; 42: 1000-4. [CrossRef]

25. Veldman BA, Spiering W, Doevendans PA, Vervoort G, Kroon AA, de Leeuw PW, et al. The Glu298Asp polymorphism of the NOS3 gene as determinant of the baseline production of nitric oxide. J Hypertens 2002; 20: 2023-7. [CrossRef]

26. Senturk N, Kara N, Aydin F, Gunes S, Yuksel EP, Canturk T, et al. Association of eNOS gene polymorphism (Glu298Asp) with psoriasis. J Dermatol Sci 2006; 44: 52-5. [CrossRef]

27. Ogretmen Z, Hiz MM, Silan F, Uludag A, Ozdemirc O. Association of endothelial nitric oxide synthase Glu298Asp gene polymorphism in psoriasis cases with hypertension. Ann Saudi Med 2014; 34: 340-5. [CrossRef]

28. Zhang MX, Zhang C, Shen YH, Wang J, Li XN, Zhang Y, et al. Biogenesis of short intronic repeat 27-nucleotide small RNA from endothelial nitric-oxide synthase gene. J Biol Chem 2008; 283: 14685-93. [CrossRef]

29. Nadaud S, Bonnardeaux A, Lathrop M, Soubrier F. Gene structure, polymorphism and mapping of the human endothelial nitric oxide synthase gene. Biochem Biophys Res Commun 1994; 198: 1027-33. [CrossRef]

Cite this article as: Pehlivan S, İnalöz S, Nursal AF, Gülel A, Pehlivan $M$. Is there any Association between the Functional Variants of the NOS3 Gene and Psoriasis? İstanbul Med J 2018; 19: 152-7. 